\title{
AUTOMATED MODEL UPDATING OF A MASONRY HISTORICAL CHURCH BASED ON OPERATIONAL MODAL ANALYSIS: THE CASE STUDY OF SAN GIOVANNI IN MACERATA
}

\author{
SILVIA SANTINI ${ }^{1}$, CARLO BAGGIO ${ }^{1}$, ENRICO DA GAI ${ }^{2}$, \\ VALERIO SABBATINI ${ }^{*}$ AND CLAUDIO SEBASTIANI ${ }^{1}$
}

\author{
${ }^{1}$ Roma Tre University, Department of Architecture \\ Largo Giovanni Battista Marzi 10, 00153, Rome, Italy \\ Email: valerio.sabbatini@uniroma3.it (*corresponding author) \\ ${ }^{2}$ Studio Da Gai Architetti Roma \\ Via Padre Raffaele Melis, 17, 00176, Rome, Italy \\ E-mail: info@enricodagai.it
}

Keywords: Historical Masonry, Ambient Vibration Test, Operational Modal Analysis,

Automated Model Updating, Douglas-Reid Method

\begin{abstract}
Over the past few decades, the conservation and seismic assessment of historical buildings has gained great importance. In particular, the prediction of the dynamic response of masonry constructions plays a central role in retrofitting and conservation interventions. Finite element modelling has become the most common and accessible approach to study the behavior of complex masonry structures, however, the gap between numerical and experimental analysis may lead to erroneous results.

This work describes the model updating procedure applied to the finite element model of San Giovanni's church in Macerata, condemned in October 2016 after the Central Italy Earthquake. The laboratory of Proof and Research on Structures and Materials of Roma Tre University carried out an extensive in-situ testing campaign including geometric survey, video endoscopy, flat-jack test, sonic tomography and ambient vibrations test in order to investigate the state of the building. The work involved both numerical and experimental analysis: the results of the testing campaign were interpreted and correlated with an accurate finite element model developed with the software Midas Gen. Operational modal analysis was performed in order to extract the modal parameters of the building (modal frequencies, shape vectors and modal damping). Material characteristics and boundary conditions were updated according to the Douglas-Reid method. In the end, the final model was compared to the initial model to evaluate and discuss the process.
\end{abstract}




\section{INTRODUCTION}

The field of structural analysis has developed sophisticated numerical models able to predict the response of complex constructions. Typically, conservation and restoration practices rely on Finite Element Models (FEM) to perform structural analysis of non-linear composite materials (such as masonry) which are otherwise hard to predict. However, the results obtained from the numerical analysis occasionally differ significantly from the real response of the structure. For this reason, it is fundamental to implement multiple strategies able to describe the structural behavior of these constructions.

Model Updating is a widely used technique used for the calibration and improvement of FEM based on reference values, therefore it is possible to link this tool with Ambient Vibration Test (AVT) and Operational Modal Analysis (OMA). AVT is a powerful dynamic monitoring technique that returns information on the overall behavior of the structure through the use of environmental excitations. The results of the AVT are usually processed with the Operational Modal Analysis (OMA) in order to estimate the modal parameters of the construction. This strategy, integrated with ordinary on-site testing, allows a global and detailed characterization of the structure. This paper describes the model updating procedure applied to the Church of San Giovanni in Macerata through the Douglas-Reid method.

\section{SAN GIOVANNI IN MACERATA}

The church of San Giovanni is an aggregate of historical buildings, placed in the south-west area of the historic center of Macerata, between "Piazza Vittorio Veneto and the beginning of
"Corso della Repubblice".
San Giovanni was designed by the Architect Rosatb Rosati, who conceived the building
based on the Church of San Carlo ai Catinari in Rome [1]. The architectare respects the typical
style of the Jesuit's order: Latin cross plan, single wi de nave, several deep side chapels, impressive dome with a tall lantern and the bell tower [2]. San Giovanni was founded in 1600

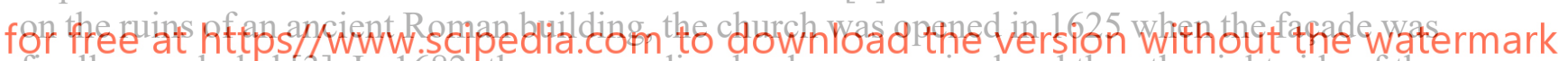
finally concluded [3]. In 1682, the surrounding land was acquired and then the right side of the transept and the bell tower were erected. The construction of the dome suffered numerous delays but finally in 1762 the entire construction was completed [4].

\section{ONSITE INVESTIGATION AND PRELIMINARY MODEL}

\subsection{Onsite test}

From November 2018 to July 2019, the PRiSMa Lab. (Laboratory of Proof and Research on Structures and Materials) from the Architecture Department of Roma Tre University, carried out an extensive experimental campaign on San Giovanni.

During the onsite campaign different tests were performed: 4 double flat jack tests, 5 Ambient Vibration Tests, 47 video endoscopy inspections, 2 sonic topographies and 20 dynamic penetrometer tests of the mortar joints.

In the present work, only the five AVT and the double flat jack tests were considered. Figure 1 illustrates the ground floor and the basement plans of the church with the locations of the double flat jack tests, in Table 1 are shown the results obtained from these tests. 

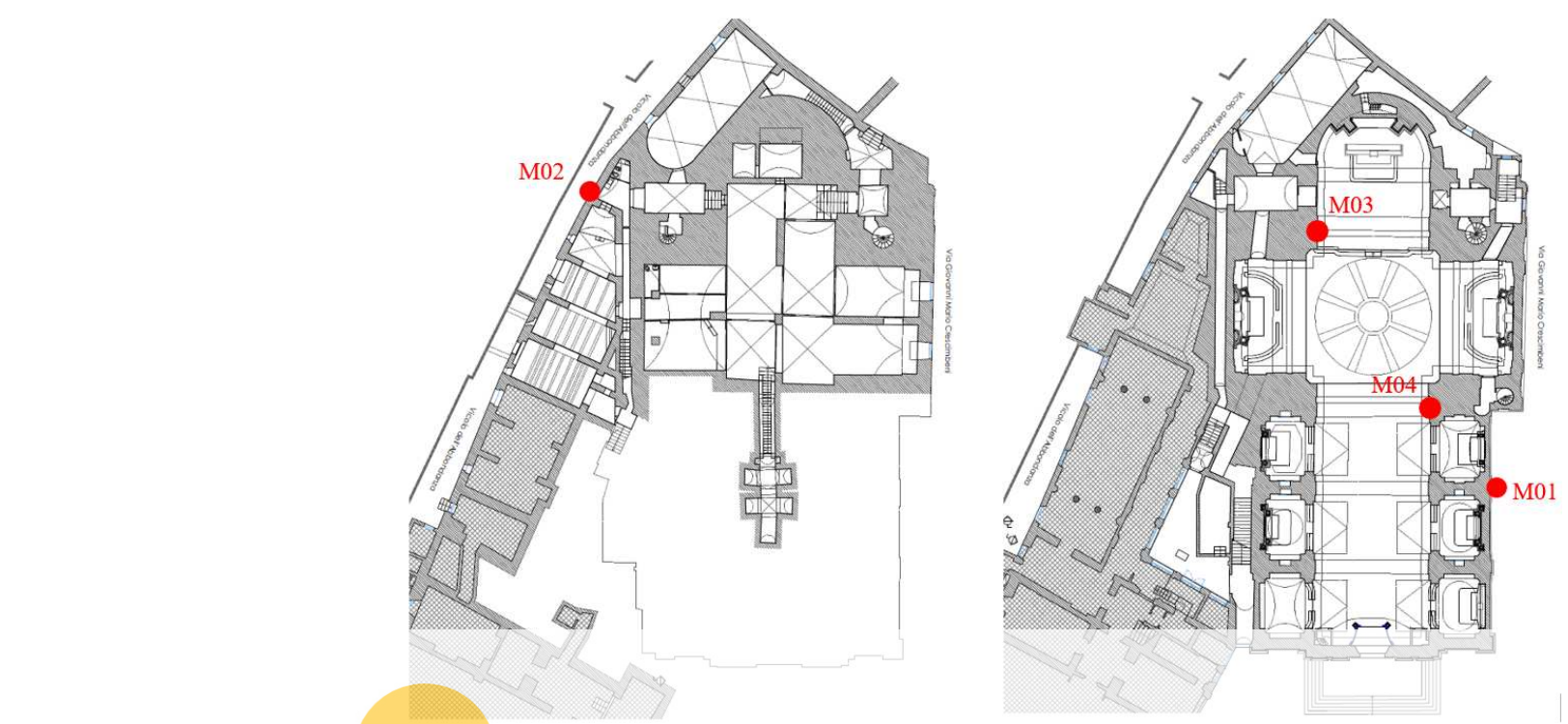

Figure 1 Double flat jacks test plan

Table 1 Results of the double flat jack tests

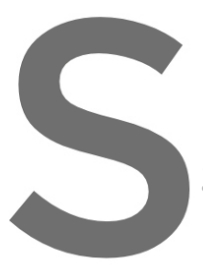

3.2 FINITE ELEMIENT MODE.I

A preliminary FEM of the entire church of S
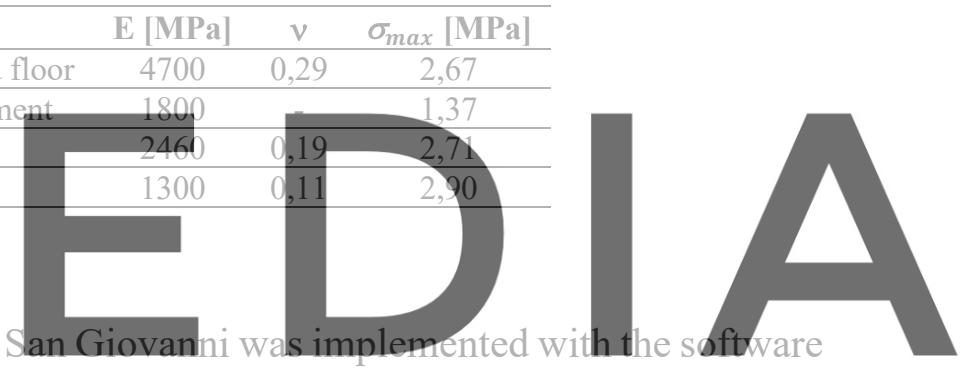

Midas Gen [5]. The construction was modeled with 13416 nodes and 6281 three-dimensional

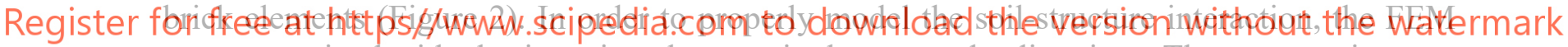
was constrained with elastic spring elements in the $\mathrm{x}, \mathrm{y}$ and $\mathrm{z}$ directions. The construction was divided into nine different volumes, each one with isotropic homogeneous elastic material with different characteristics. The Young modules and the Poisson's ratio were evaluated according to the results of the four double flat jack tests as reported in Table 2.

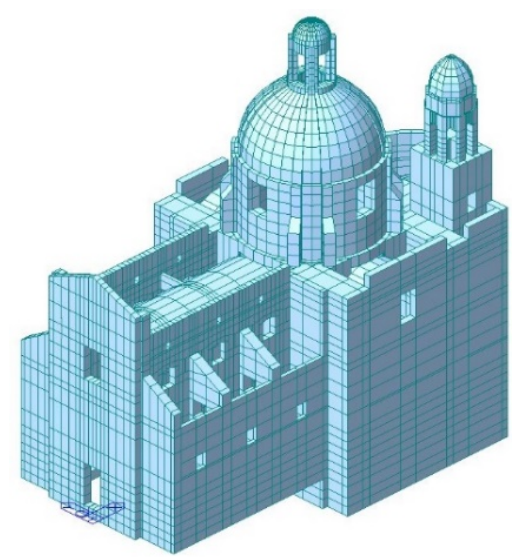

Figure 2 Finite Element Model of San Giovanni in Macerata 
Table 2 Double flat jacks result implementation

\begin{tabular}{cccc}
\hline Test implementation & Element & E [MPa] & $\boldsymbol{v}$ \\
\hline M01 & Nave & 4700 & 0,29 \\
\hline M03 & Pillar 3 & 2460 & 0,19 \\
\hline M04 & Pillar 4 & 1300 & 0,11 \\
\hline Average of M03, M04 & Pillar 1 and 2 & 1880 & 0,15 \\
\hline Average of M01, M02, M03, M04 & Dome, tower, façade and apse & 2565 & 0,20 \\
\hline
\end{tabular}

\section{AMBIENT VIBRATION TEST}

The response in acceleration of the construction was recorded in 5 different runs, each run was recorded with 12 uniaxial ICP piezoelectric accelerometers $\left(n^{\circ} 10\right.$ PCB 393B12 with $8 \mu \mathrm{g}$ rms resolution and $\mathrm{n}^{\circ} 2$ PCB 393B 31 with $1 \mu \mathrm{g}$ rms resolution, all of them with $10 \mathrm{~V} / \mathrm{g}$ sensitivity and range $\pm 0,5 \mathrm{~g}$ ) for about 45 minutes. In the end, there were measured a total of 16 different points located at four different heights: nave level (14m), drum level $(22 \mathrm{~m})$, dome level (29m) and lantern level $(36 \mathrm{~m})$. The sensors were connected to a 24-bit acquisition system which recorded with a sample frequency of $441 \mathrm{~Hz}$.

\subsection{Multi Run Operational Modal Analysis}

OMA is a technique used to process the results from output-only measurements (AVT), the hypothesis of white noise conditions allows to neglect the recording of the input, in this circumstances all the patural frequencies of the structure are assumed to be excited [6] [7].

The modal parameter was carried out using the implemented in the software Simeenter position of the accelerometers, it was adopted technique allows to scale the modes based on the most appro

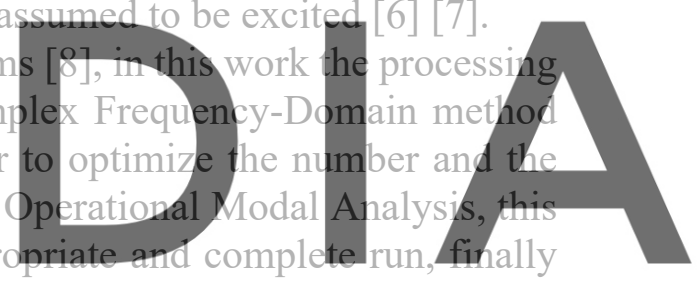
the results are merged to return the global behavior of the construction. In this work five

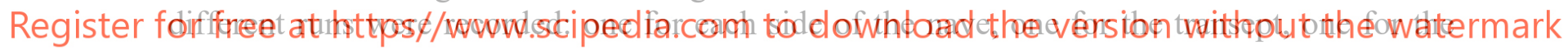
drum and one on the extrados of the dome and lantern maintaining three common reference sensors during all the acquisitions [10].

The results are reported in Figure 3, the analysis was limited to the first three modes of vibration because the most reliable since the complex structure is part of a large irregular building aggregate that requires a relevant amount of energy to excite the higher modes thus it makes them difficult to identify and validate [11].
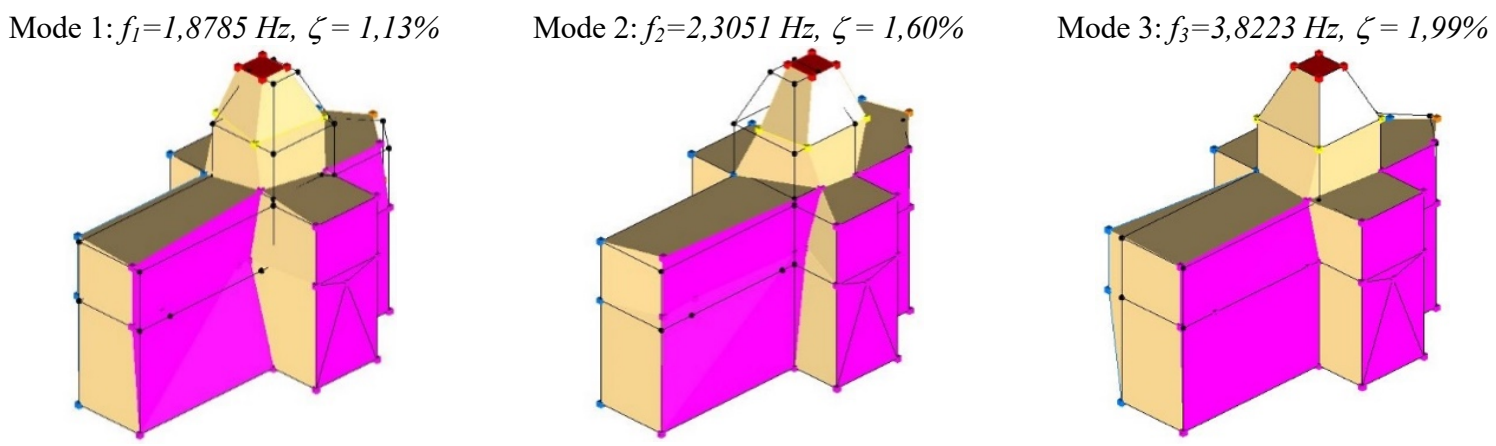
Figure 3 Experimental results from Multi run Operational Modal Analysis

\section{MODEL UPDATING}

The relevant parameters of the FEM were tuned in order to improve the correspondence with the experimental results. This process requires a set of preparatory phases. Initially, it is necessary to improve the preliminary model through the Manual Tuning (par. 5.1) of the parameters. Subsequently, Sensitivity Analysis (par. 5.2) is suggested to identify the relevant factors that strongly influence the behaviour of the structure. Based on the previous results, the automated Model Updating can be finally performed according to the Douglas-Reid method (par. 5.3) [12] [13].

\subsection{Manual Tuning}

In a dynamic system, the modal quantities are dependent on the mass, the stiffness, the damping and the boundary conditions of the model. During the Manual Tuning, these parameters are varied intuitively in order to approximate the experimental results [14].

Often the elastic constrains (boundary conditions) have more influence than the other parameters on the dynamic behavior of the construction [7]. Several numerical eigenvalue analyses were carried out with different stiffnesses of the springs in foundation. The relative frequency error with the variation of the elasticity was evaluated according to (1) and plotted in Figure 4. The minimum error corresponded to a value of stiffness equal to $10^{6} \mathrm{~N} / \mathrm{mm}$.
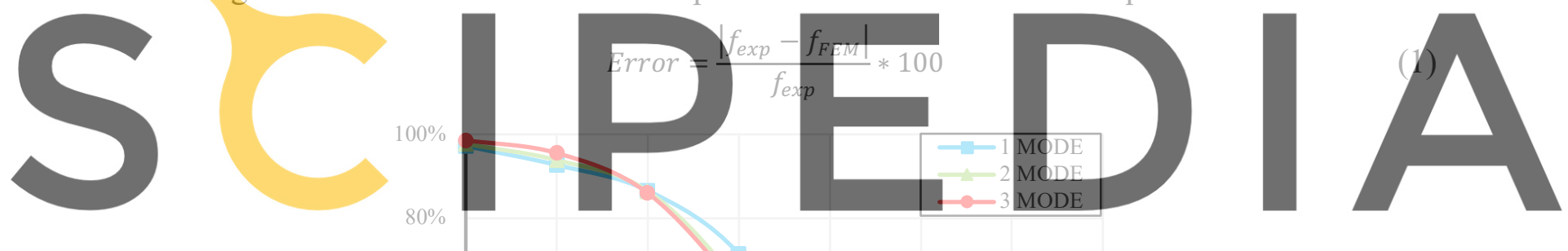

Register for free at htțps/\%www.scipedia.com to download the version without the watermark

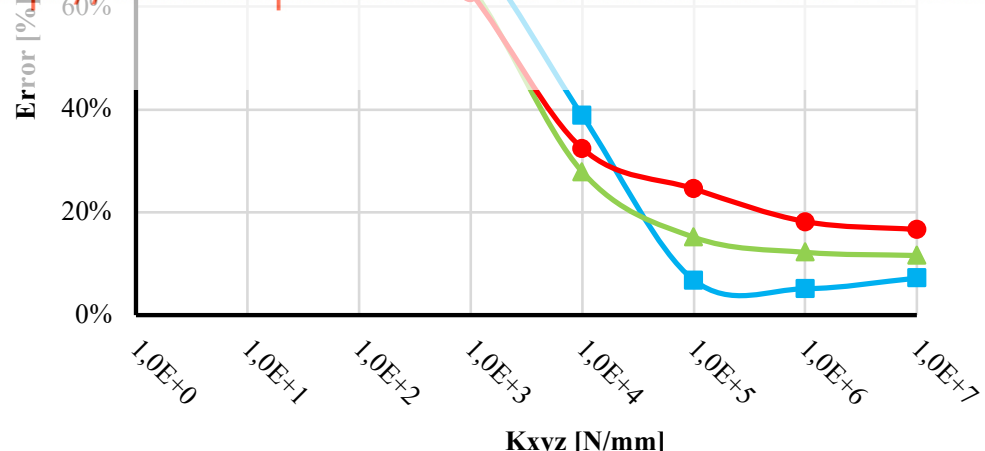

Figure 4 Relative frequency error with the variation of the soil stiffness

\subsection{The Sensitivity Analysis}

Every parameter of a FEM has a different influence on the global behavior depending on the geometry, the heterogeneity of the materials and the interaction between the elements. The Sensitivity Analysis identifies the parameters that mostly affect the response of the model [15] and it quantifies their influence with the sensitivity coefficient defined in (2) [16]. 


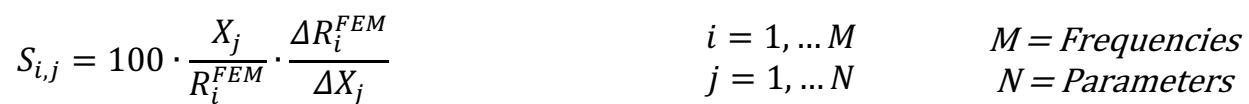

- $\quad X_{j}$ represents the $j$-th model parameter;

- $\quad R_{i}^{F E M}$ represents the $i$-th output of the analysis (in this case the natural frequencies);

- $\Delta X_{j}$ represents the range of variation of the model parameter;

- $\Delta R_{i}^{F E M}$ represents the variation of the output of the analysis;

The Sensitivity Analysis was performed starting from the values obtained from the four double flat jack tests (par. 3.2) [17], the parameters were varied with an increment of 5\%.

The parameters with the highest sensitivity coefficients resulted the most influential; based on the results of Table 3, the parameters E3, E4, E5, E6, E7 were selected in addition to the previously analyzed stiffness of the spring elements in foundation $\mathrm{K}_{\mathrm{x}}, \mathrm{K}_{\mathrm{y}}$ and $\mathrm{K}_{\mathrm{z}}$ (par. 5.1).
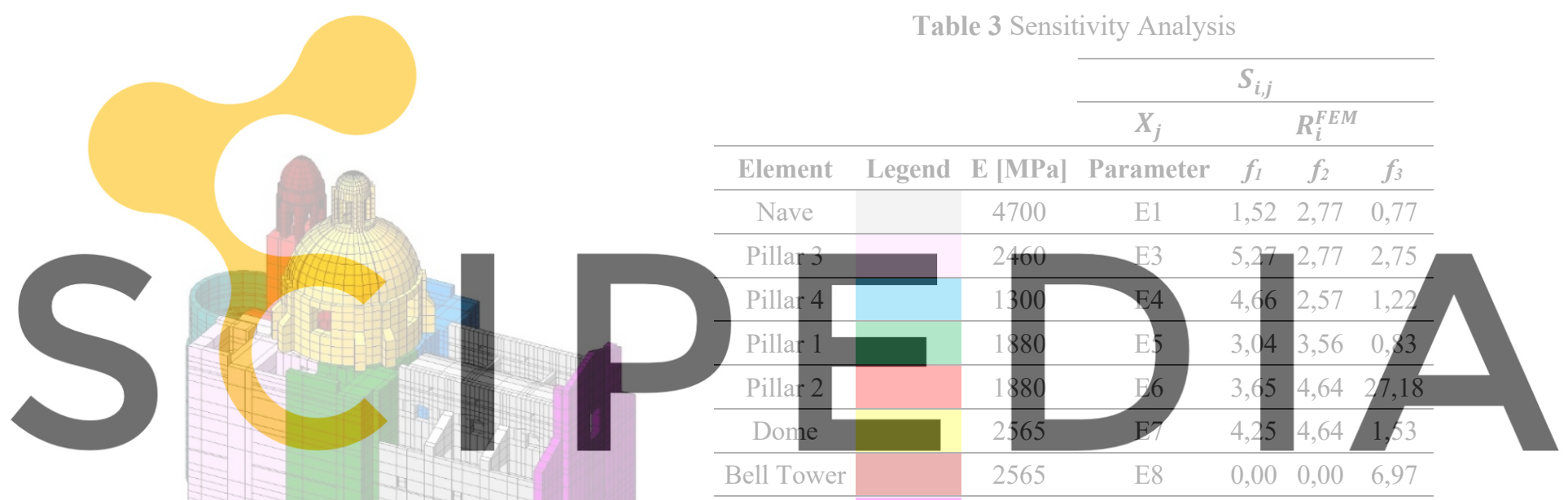

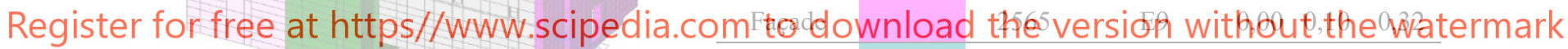

\subsection{The Douglas-Reid method}

The Douglas-Reid method [18] is a simplified procedure introduced in 1982 to minimize the error between two sets of data considering different combinations of parameters. In this work, the Douglas-Reid method was applied to minimize the error between the numerical natural frequencies of the FEM and the experimental frequencies of the OMA.

The experimental observations resulted from the OMA, indicated as $R_{i}^{E X P}$ with $1 \leq i \leq \mathrm{M}$ (M represents the total number of experimental observations), are compared with the related $R_{i}^{F E M}$ values obtained from the analysis of the FEM, function of $\mathrm{N}$ significant structural parameter indicated with $X_{k}(3)$.

$$
R_{i}^{F E M}=R_{i}^{F E M}\left(X_{1}, X_{2}, X_{3}, \ldots, X_{k}, \ldots, X_{N}\right)
$$

In order to reduce the error between $R_{i}^{F E M}$ and $R_{i}^{E X P}$, the proper structural parameters $X_{k}$ are selected from the set range of values using a batch analysis procedure. 
The Douglas-Reid method uses an approximated model to interpolate with a quadratic function (4) the proper structural parameters within a range of coordinate points $\left(X_{1}, X_{2}, X_{3}, \ldots, X_{k}, \ldots, X_{N}\right)[19]$.

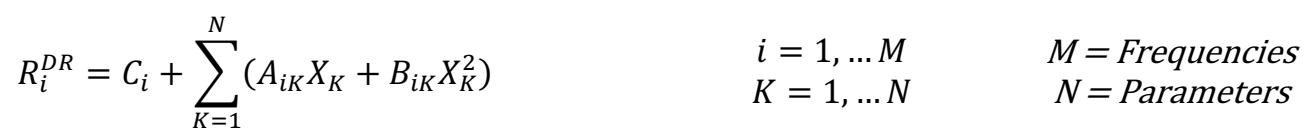

- $\quad i$ represents the $i$-th structural parameter;

- $\quad K$ represents the $k$-th significant variable in the model;

- $\quad R_{i}^{D R}$ represents the structural response of the approximated model;

- $\quad C_{i}, A_{K i}, B_{K i}$ are $2 \mathrm{~N}+1$ coefficient to be determined;

The analysis was carried out according to the following steps:

1) Definition of the lower and upper bound of variation for each parameter (5), in this case a variation of $\pm 75 \%$ was adopted on the selected parameters (par. 5.2):

$$
X_{K}^{L} \leq X_{K}^{B} \leq X_{K}^{U}
$$

2) Each variable was normalized over its nominal value (6):

$$
\frac{X_{K}^{L}}{X_{K}^{B}} \leq \frac{X_{K}^{B}}{X_{K}^{B}} \leq \frac{X_{K}^{U}}{X_{K}^{B}}
$$

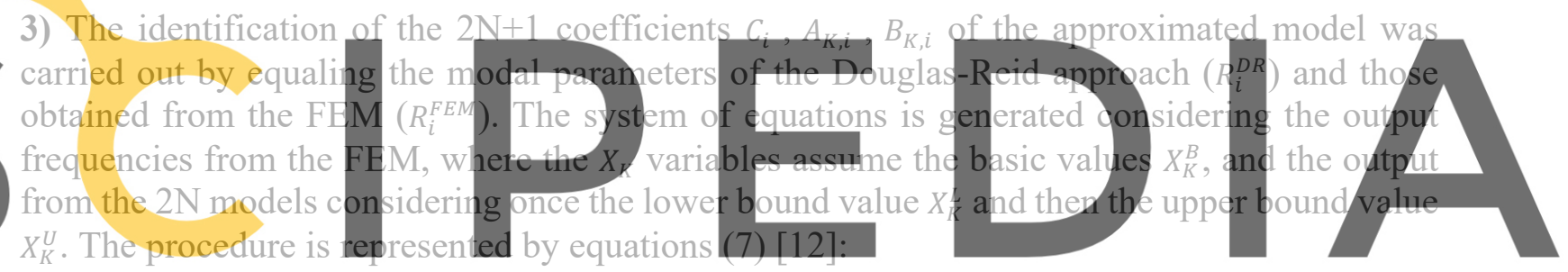

$X_{K}^{U}$. The procedure is represented by equations (7) [12]:

$$
R_{i}^{D R}\left(X_{1}^{B}, X_{2}^{B}, \ldots, X_{N}^{B}\right)=R_{i}^{F E M}\left(X_{1}^{B}, X_{2}^{B}, \ldots, X_{N}^{B}\right)
$$

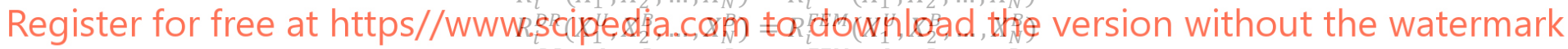

$$
\begin{aligned}
R_{i}^{D R}\left(X_{1}^{L}, X_{2}^{B}, \ldots, X_{N}^{B}\right) & =R_{i}^{F E M}\left(X_{1}^{L}, X_{2}^{B}, \ldots, X_{N}^{B}\right) \\
& \vdots \\
R_{i}^{D R}\left(X_{1}^{B}, X_{2}^{B}, \ldots, X_{N}^{U}\right) & =R_{i}^{F E M}\left(X_{1}^{B}, X_{2}^{B}, \ldots, X_{N}^{U}\right) \\
R_{i}^{D R}\left(X_{1}^{B}, X_{2}^{B}, \ldots, X_{N}^{L}\right) & =R_{i}^{F E M}\left(X_{1}^{B}, X_{2}^{B}, \ldots, X_{N}^{L}\right)
\end{aligned}
$$

4) The system of equations is also written as (8), with the matrices expressed in (9):

$$
\left\{R_{i}^{D R}\right\}=[C] \cdot\left\{K_{i}\right\}
$$

- $\left\{K_{i}\right\}$ is the vector containing the unknown coefficients $C_{i}, A_{K, i}, B_{K, i}$;

- $\quad[C]$ is the matrix containing the combinations of the variables;

$$
[C]=\left[\begin{array}{cccccc}
1 & X_{1}^{B} & X_{1}^{B^{2}} & & X_{N}^{B} & X_{N}^{B^{2}} \\
1 & X_{1}^{U} & X_{1}^{U^{2}} & \cdots & X_{N}^{B} & X_{1}^{B^{2}} \\
1 & X_{1}^{L} & X_{1}^{L^{2}} & & X_{N}^{B} & X_{1}^{B^{2}} \\
& \vdots & & \ddots & & \vdots \\
1 & X_{1}^{B} & X_{1}^{B^{2}} & & X_{N}^{U} & X_{1}^{U^{2}} \\
1 & X_{1}^{B} & X_{1}^{B^{2}} & \cdots & X_{N}^{L} & X_{1}^{L^{2}}
\end{array}\right] \quad ;\left\{K_{i}\right\}=\left\{\begin{array}{c}
C_{i, 1} \\
A_{i, 1} \\
B_{i, 1} \\
\vdots \\
A_{i, N} \\
B_{i, N}
\end{array}\right\}
$$


5) The system of equations is solved according to (10). Therefore, it is defined a matrix of the constants $[K]$ containing all the vectors $\left\{K_{i}\right\}$ as shown in (11):

$$
\begin{gathered}
\left\{K_{i}\right\}=[C]^{-1}\left\{R_{i}^{D R}\right\} \\
{[K]=\left[\begin{array}{c}
\left\{K_{1}\right\} \\
\left\{K_{2}\right\} \\
\vdots \\
\left\{K_{M}\right\}
\end{array}\right]}
\end{gathered}
$$

Finally, it is defined $R^{D R}$ as shown in (12) and (13):

$$
\left\{R^{D R}\right\}=[K] \cdot\{x\}
$$

$$
[K]=\left[\begin{array}{cccccc}
C_{1,1} & A_{1,1} & B_{1,1} & \ldots & A_{1, N} & B_{1, N} \\
C_{2,1} & A_{2,1} & B_{2,1} & & A_{2, N} & B_{2, N} \\
& \vdots & & \ddots & \vdots & \vdots \\
C_{M, 1} & A_{M, 1} & B_{M, 1} & \cdots & A_{M, N} & B_{M, N}
\end{array}\right] \quad ;\{x\}=\left\{\begin{array}{c}
1 \\
X_{1} \\
X_{1}^{2} \\
\vdots \\
X_{N} \\
X_{N}^{2}
\end{array}\right\}
$$

6) The objective function is defined in (14) [12]:

$$
f(x)=\sum W \cdot\left(R^{D R}-R^{E X P}\right)^{2} \quad ; W=\left(\frac{1}{R^{E X P^{2}}}\right)
$$

$W$ is a diagonal matrix necessary to normalize $R D R-R^{E X P}$ since $R^{E X P}$ can reach different orders
of magnitude. In this work, it was used the algorithm "fmincon" (findminimum of constrained
nonlinear multivariable function) present in the software MATLAB [20] in order to miningize
the objective function (14).
The optimized parameters result in the vector $\{x\}$ previously definedin $(13)$.

\subsection{Results}

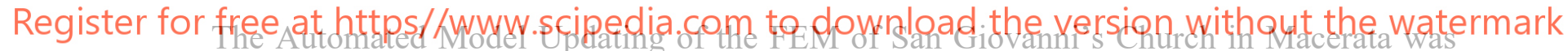

implemented with the Douglas-Reid method considering E3, E4, E5, E6, E7 and $K_{x}, K_{y}, K_{z}$ as

the significant parameters. The optimized parameters are reported in Table 4.

Table 4 Optimized parameters

\begin{tabular}{cccc}
\cline { 2 - 4 } & \multicolumn{3}{c}{ Parameters } \\
\cline { 2 - 4 } & Initial & Updated & Variation \\
\hline $\mathrm{E} 3[\mathrm{MPa}]$ & 2460 & 4305 & $75 \%$ \\
\hline $\mathrm{E} 4[\mathrm{MPa}]$ & 1300 & 325 & $-75 \%$ \\
\hline $\mathrm{E} 5[\mathrm{MPa}]$ & 1880 & 3290 & $75 \%$ \\
\hline $\mathrm{E} 6[\mathrm{MPa}]$ & 1880 & 3290 & $75 \%$ \\
\hline $\mathrm{E} 7[\mathrm{MPa}]$ & 2565 & 3073 & $20 \%$ \\
\hline $\mathrm{K}_{\mathrm{x}}[\mathrm{N} / \mathrm{mm}]$ & 1000000 & 1520033 & $52 \%$ \\
\hline $\mathrm{K}_{\mathrm{y}}[\mathrm{N} / \mathrm{mm}]$ & 1000000 & 1562838 & $56 \%$ \\
\hline $\mathrm{K}_{z}[\mathrm{~N} / \mathrm{mm}]$ & 1000000 & 1749302 & $75 \%$ \\
\hline
\end{tabular}


The results from the updated FEM are compared to the experimental results and the initial FEM as shown in Figure 5.

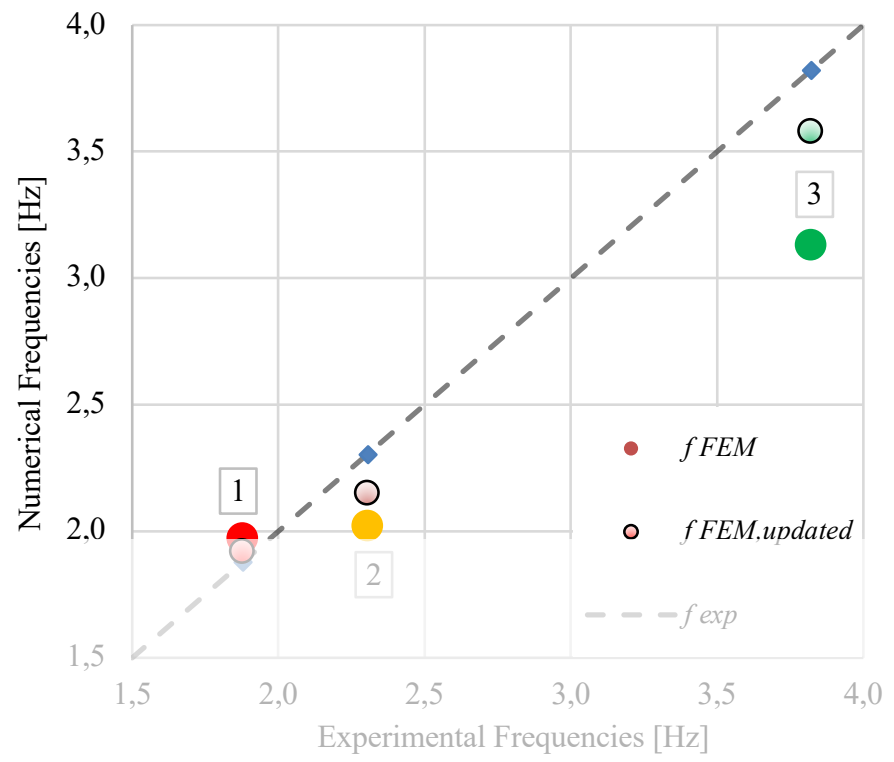

Figure 5 Frequency comparison

The frequencies from the OMA, the initial FEM and the updated FEM are reported together with their relative frequency errors (1) in Table 5 while in Figure 6 are reported the modal deflections of the updated nunnerical model.
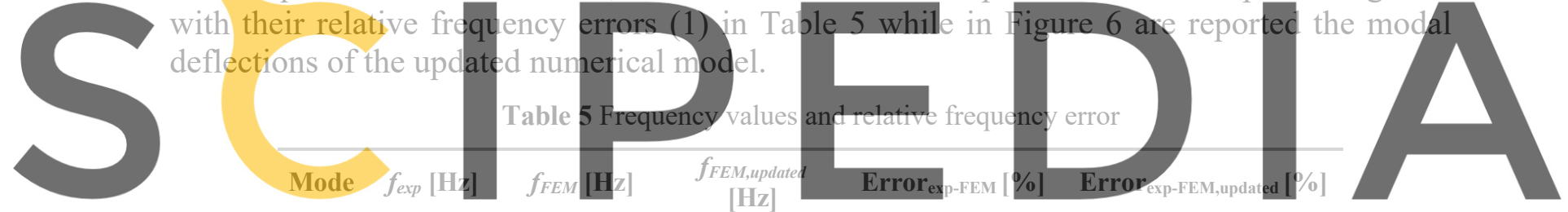

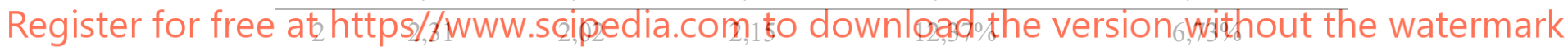

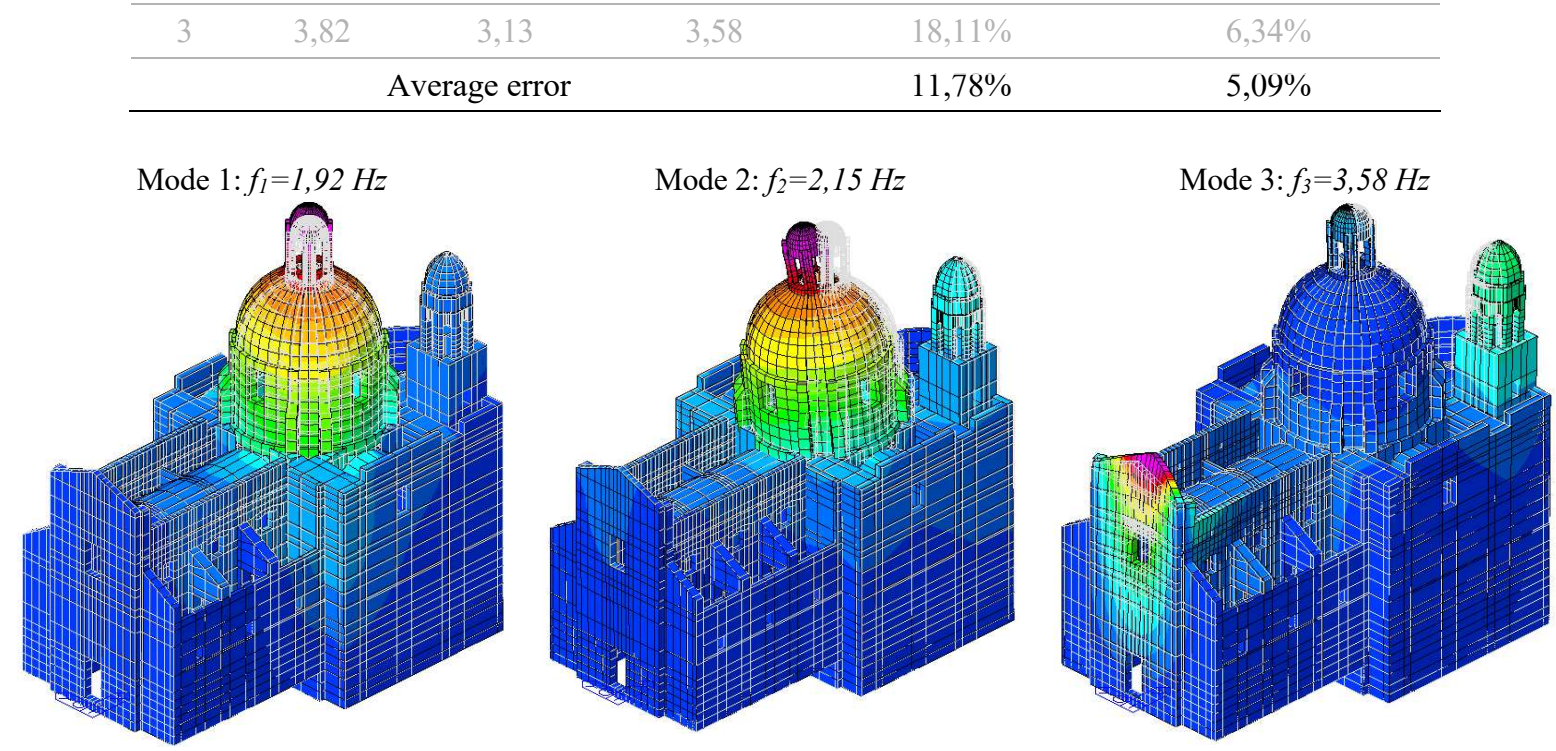

Figure 6 Numerical Modal Deformation of the Updated Model 


\section{CONCLUSIONS}

The present work aims to create a finite element model that describes, in a sufficiently reliable way, the behaviour of an historical masonry structure. In particular, an optimized model of the Church of San Giovanni in Macerata was generated through the optimization process carried out with the Douglas-Reid method. For the proper realization of the Model Updating of the finite element model there were followed different steps.

Initially, a series of investigations were carried out in order to identify the mechanical characteristics of the materials and the current state of the construction. Once the on-site testing was completed, it was elaborated a preliminary FEM to provide an indication on the behaviour of the structure. Subsequently, the dynamic characterization of the church was carried out through the Multi Run Operational Modal Analysis. This technique identified, using the Polymax algorithm, the modes of vibration and the modal properties of the building (frequencies and damping). In order to achieve an adequate accuracy before the model updating, it was essential to calibrate the stiffness of the ground through the Manual Tuning procedure. A Sensitivity Analysis of the structural parameters investigated was subsequently carried out in order to understand the influence of the main parameters on the dynamics of the church. After the preparatory steps were completed, the Automated Model Updating according to the Douglas-Reid method was performed.

The updating of the parameters highlights a consistent variation of the modulus of elasticity of the pillars that sustain the dome and the stiffness of the foundations in the vertical direction.

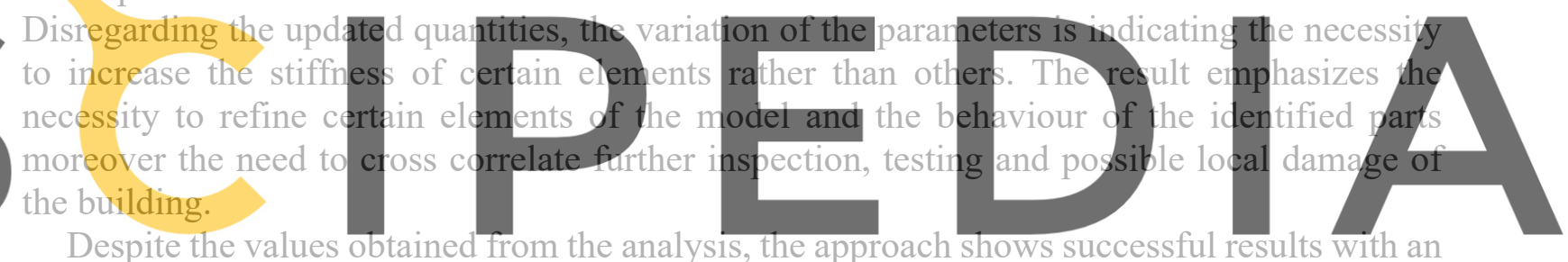

Despite the values obtained from the analysis, the approach shows successful results with an overall improvement of the updated numerical frequencies of 6,7\% from the initial FEM.

Register for free at https//www.scipedia.com to download the version without the watermark BIBLIOGRAPHY

[1] O. Gentili, "Memorie storiche raccolte," in Macerata sacra, Recanati, Simboli, 1947, p. 167.

[2] Archivio Priorale di Macerata, Instrumentorum, n. 858, Macerata: Archivio di Stato di Macerata (ASM), 1606-1609.

[3] P. Pirri, "Giovanni Tristano e i primordi dell'architettura gesuitica," Roma, 1955, p. 39.

[4] G. Cruciani-Fabozzi, "Rosato Rosati e l'architettura maceratese del Seicento," in "Vita e cultura del Seicento nella Marca", Macerata, 1977.

[5] MIDAS Information Technology Co., "Midas Gen v1.1," 2015.

[6] R. Brincker and C. Ventura, Introduction to Operational Modal Analysis, Wiley, 2015.

[7] C. Gentile and A. Saisi, "Ambient vibration testing of historic masonry towers for structural identification and damage assessment," Construction and Building Materials, pp. 1311-1321, 2006. 
[8] M. G. Masciotta and L. F. Ramos, "Dynamic Identification of Historica Masonry Structures," in Long-term performance and durability of masonry structures, Woodhead Publishing Series in Civil and Structural Engineering, 2019, pp. 241-264.

[9] S. I. S. NV, "Simcenter Testlab Version 18.0," 2018.

[10] C. Baggio, V. Sabbatini, S. Santini and C. Sebastiani, "'Multi-Run Operational Modal Analysis of a masonry historical church: the case study of San Giovanni in Macerata," in Rehabend 8th Euro-American COngress, Granada, 2020.

[11] A. De Stefano, E. Matta and P. Clemente, "Structural health monitoring of historical heritage in Italy: some relevant experiences," Journal of Civil Structural Health Monitoring, pp. 83-106, 2016.

[12] T. Zordan, B. Briseghella and T. Liu, "Finite element model updating of a tied-arch bridge using Douglas-Reid method and Rosenbrock optimization algorithm," Journal of Traffic and Transportation Engineering, pp. 280-292, 2014.

[13] C. Costa, A. Arede, A. Costa, E. Caetano, A. Cunha and F. Magalhaes, "Updating Numerical Models of Masonry Arch Bridges by Operational Modal Analysis," International Journal of Architectural Heritage, pp. 760-774, 2015.

[14] C. Baggio, V. Sabbatini and S. Santini, "Model Updating of a Masonry Historical Church based on Operational Modal Analysis: the case study of San Filippo Neri in Macerata," in 7th International Conference on Computational Methods in Structural Dynamics and Earthquake Engineering, Crete, Greece, 24-26 June 2019.

[15] M. Acito, C. Chesi, C. Lazzarin and E. Richermo, "Historical reinforced concrete arch bridges: Dynamic identification and seismic vulnerability assessment," Insights and Innovations in Structural Engineering, Mechanics and Computation, 2016.

[16] A. De Stefano, R. Ceravolo, E. Matta, A. Quattrone and L. Zanotti, "Identificazione dinamica sperimentale di edifici strategici sotto sisma," Ingenio. Informazione tecnica e progettuale, 12 Aprile 2012.

[17] C. Gentile, "Modal and structural identification of a R.C. arch bridge," Structural Engineering and Mechanics, pp. 53-70, 2006.

[18] B. M. Douglas and W. H. Reid, "Dynamic Tests and System Identification of Bridges," Journal of the Structural Division, pp. 2295-2312, 1982.

[19] A. Cabbai, C. Gentile and A. Saisi, "Frequency tracking and F.E. model identification of a masonry tower," in 5th International Operational Modal Analysis Conference, Guimaraes, Portugal, 2013.

[20] Simulink, "MATLAB R2019a". 